\title{
ANALYSIS OF LAND SUBSIDENCE MONITORING IN MINING AREA WITH TIME-SERIES INSAR TECHNOLOGY
}

\author{
N. Sun ${ }^{1}$, Y. J. Wang ${ }^{1}$ \\ ${ }^{1}$ The Basis Srveying and Mappinglnsistute of Liaoning Provinc, China - xunyicaojiushiwo@ 163.com
}

KEY WORDS: Time-series, InSAR, Land Subsidence, ALOS PALSAR, RADARSAT-2

\begin{abstract}
:
Time-series InSAR technology has become a popular land subsidence monitoring method in recent years, because of its advantages such as high accuracy, wide area, low expenditure, intensive monitoring points and free from accessibility restrictions. In this paper, we applied two kinds of satellite data, ALOS PALSAR and RADARSAT-2, to get the subsidence monitoring results of the study area in two time periods by time-series InSAR technology. By analyzing the deformation range, rate and amount, the time-series analysis of land subsidence in mining area was realized. The results show that InSAR technology could be used to monitor land subsidence in large area and meet the demand of subsidence monitoring in mining area.
\end{abstract}

\section{INTRODUCTION}

It is well known that the mining of underground mineral resources can easily produce ground subsidence. The larger mining amount and the longer mining time make the subsidence more obvious. Serious land subsidence will form collapse pits, ground fissures, and some even form large area of water accumulation pits, which threaten the safety of life and property of local residents and bring huge economic losses.

The traditional monitoring method of mining subsidence is Leveling and GPS, etc. Due to the sparse measurement points and long interval of retest time, these methods can hardly meet the requirements of large area continuous measurements. And these methods have defects, such as wasting time, energy and financial. In addition, the measurement points are difficult to protect (Wang et al., 2014; Liu et al., 2005). Since the idea of synthetic aperture radar interferometry was first proposed in 1974, InSAR technology has developed rapidly. It provides a new technical means for land subsidence monitoring, because of it has the ability of working all-weather situation and all-day, etc. References (Hayman et al., 2010; Jiang et al., 2011; Yin et al., 2011) have realized the subsidence monitoring of mining area by time-series InSAR technology. Although there are still some problems to be improved, but there is no denying that with the in- depth study of InSAR technology, the realization of engineering monitoring is the trend of the future. This paper takes a mining area as the experimental area, and uses time-series InSAR technology to monitor the land subsidence. This paper realized the time-series analysis of the deformation results by using two satellite images, ALOS PALSAR and RadarSat-2, time spans nearly 10 years.

\section{ACQUISITION OF LAND SUBSIDENCE INFORMATION IN MINING AREA BY INSAR TECHNOLOGY}

\subsection{Time-series InSAR Technology}

References (Ferretti et al., 1999; Mora et al., 2001; Zhang et al.,2009; Zhang et al.,2012) have analyzed and applied the timeseries InSAR technology by different ways, so not tired in words here. In this paper, GDEMSI and Gamma software are used to realize the data processing, including radar data preprocessing, stable points extraction, Delaunay triangulation establishment, linear deformation estimation, separation and estimation of nonlinear deformation with atmospheric phase, total deformation estimation, etc. 


\subsection{Data Selection}

According to previous experience, data selection mainly considers these factors, as follows:

(1) The images completely cover the survey area. The dates of data are continuous and the number of them are sufficient. Then make sure the data fit the time-series analysis.

(2) The wavelength of the data is long enough, and the penetration is strong, which is suitable for the large deformation monitoring in the mining area.

Through data analysis, two kinds of data are selected in this paper: The first one is ALOS-PALSAR data in L-band, from January 2007 to January 2011, 23 scenes; The other one is RadarSat-2 data in C-band, from March 2015 to May 2017, 32 scenes. Table 1 and Table 2 are the baseline information of the data.

Table 1. Baseline analysis of ALOS-PALSAR data

\begin{tabular}{|c|c|c|c|c|c|c|c|}
\hline Number & Imaging Date & $\begin{array}{c}\text { Vertical baseline } \\
\text { distance } / \mathrm{m}\end{array}$ & $\begin{array}{c}\text { Time baseline } \\
\text { distance/day }\end{array}$ & Number & Imaging Date & $\begin{array}{c}\text { Vertical baseline } \\
\text { distance /m }\end{array}$ & $\begin{array}{c}\text { Time baseline } \\
\text { distance/day }\end{array}$ \\
\hline $\mathbf{1}$ & 20070119 & 0.00 & 0 & 13 & 20090727 & 882.70 & 920 \\
\hline $\mathbf{2}$ & 20070722 & 2380.46 & 184 & 14 & 20090911 & 1396.02 & 966 \\
\hline $\mathbf{3}$ & 20070906 & 2608.02 & 230 & 15 & 20091027 & 1719.34 & 1012 \\
\hline $\mathbf{4}$ & 20071022 & 2914.41 & 276 & 16 & 20100314 & 3114.97 & 1150 \\
\hline $\mathbf{5}$ & 20080122 & 3562.10 & 368 & 17 & 20100429 & 3219.38 & 1196 \\
\hline $\mathbf{6}$ & 20080423 & 4788.79 & 460 & 18 & 20100614 & 3227.17 & 1242 \\
\hline $\mathbf{7}$ & 20080608 & 4783.09 & 506 & 19 & 20100730 & 3580.81 & 1288 \\
\hline $\mathbf{8}$ & 20080724 & 1327.01 & 552 & 20 & 20100914 & 3640.02 & 1334 \\
\hline $\mathbf{9}$ & 20081024 & -572.78 & 644 & 21 & 20101030 & 4107.78 & 1380 \\
\hline $\mathbf{1 0}$ & 20090124 & 119.90 & 736 & 22 & 20101215 & 4199.33 & 1426 \\
\hline $\mathbf{1 1}$ & 20090311 & 684.83 & 782 & 23 & 20110130 & 4869.91 & 1472 \\
\hline $\mathbf{1 2}$ & 20090611 & 784.45 & 874 & & & & \\
\hline
\end{tabular}

Table 2. Baseline analysis of RadarSat-2 data

\begin{tabular}{|c|c|c|c|c|c|c|c|}
\hline Number & Imaging Date & $\begin{array}{c}\text { Vertical baseline } \\
\text { distance } / \mathrm{m}\end{array}$ & $\begin{array}{c}\text { Time baseline } \\
\text { distance/day }\end{array}$ & Number & Imaging Date & $\begin{array}{c}\text { Vertical baseline } \\
\text { distance /m }\end{array}$ & $\begin{array}{c}\text { Time baseline } \\
\text { distance/day }\end{array}$ \\
\hline $\mathbf{1}$ & 20150312 & 0 & 0 & 17 & 20160330 & 81.07 & 384 \\
\hline $\mathbf{2}$ & 20150405 & 73.22 & 24 & 18 & 20160423 & 44.32 & 408 \\
\hline $\mathbf{3}$ & 20150429 & 122.24 & 48 & 19 & 20160517 & 124.61 & 432 \\
\hline $\mathbf{4}$ & 20150523 & 43.67 & 72 & 20 & 20160610 & 75.41 & 456 \\
\hline $\mathbf{5}$ & 20150616 & 233.74 & 96 & 21 & 20160704 & 191.88 & 480 \\
\hline $\mathbf{6}$ & 20150710 & 201.14 & 120 & 22 & 20160728 & 24.62 & 504 \\
\hline $\mathbf{7}$ & 20150803 & 43.78 & 144 & 23 & 20160821 & 212.86 & 528 \\
\hline $\mathbf{8}$ & 20150827 & 22.66 & 168 & 24 & 20160914 & 73.47 & 552 \\
\hline $\mathbf{9}$ & 20150920 & -64.18 & 192 & 25 & 20161008 & 12.80 & 576 \\
\hline $\mathbf{1 0}$ & 20151014 & 40.41 & 216 & 26 & 20161101 & 31.44 & 600 \\
\hline $\mathbf{1 1}$ & 20151107 & -49.34 & 240 & 27 & 20170112 & 243.41 & 672 \\
\hline $\mathbf{1 2}$ & 20151201 & 54.97 & 264 & 28 & 20170205 & 124.87 & 696 \\
\hline $\mathbf{1 3}$ & 20151225 & 214.63 & 288 & 29 & 20170301 & 121.04 & 720 \\
\hline $\mathbf{1 4}$ & 20160118 & -7.58 & 312 & 30 & 20170325 & 143.49 & 744 \\
\hline $\mathbf{1 5}$ & 20160211 & 101.85 & 336 & 31 & 20170418 & -66.83 & 768 \\
\hline $\mathbf{1 6}$ & 20160306 & 82.47 & 360 & 32 & 20170512 & 82.26 & 792 \\
\hline
\end{tabular}




\subsection{Data Processing}

After data preprocessing, extract the stable highly coherent point target, then calculate relative linear change rate and relative elevation error of each two points via model coherence coefficient. A highly coherent point with known variables and DEM error is chosen as the reference point. Integrate the relative linear change rate and relative elevation error of each two highly coherent points, and then get the linear deformation rate and height error of each point target. Finally, separate the nonlinear deformation phase and atmospheric influence phase base on residual phase, then obtain the time-series deformation results according to the linear and nonlinear deformation phase. The first stage data is processed by GDEMSI software, time baseline is $650 \mathrm{~d}$, spatial baseline is $1400 \mathrm{~m}$, and 62 interference pairs are generated. Figure 1 is the small baseline spatiotemporal distribution of the first stage data. The second stage data is processed by Gamma software, time baseline is $120 \mathrm{~d}$, space baseline is $212 \mathrm{~m}$, and 69 interference pairs are generated. Figure 2 is the small baseline spatiotemporal distribution of the second stage data.

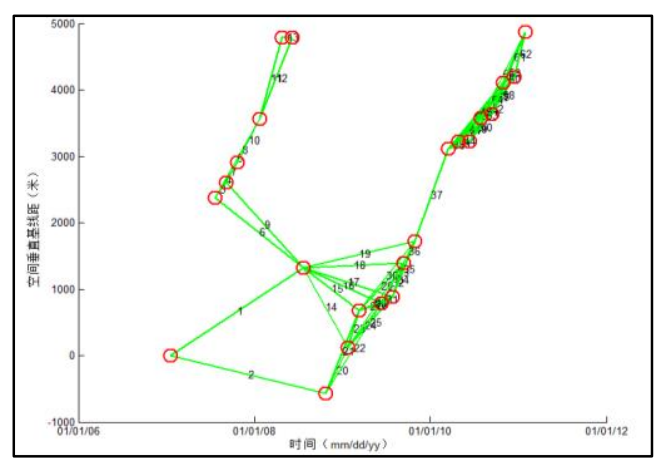

Figure 1. The small baseline spatiotemporal distribution of the first stage data

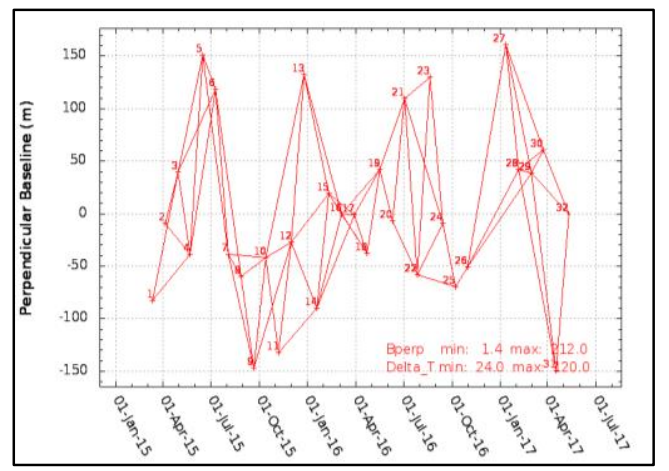

Figure 2. The small baseline spatiotemporal distribution of the second stage data

\subsection{Land Subsidence Information}

\subsubsection{Deformation Rate and Deformation Amount:Through} 2.3 data processing, we obtain the linear deformation rate and deformation amount in two periods. Figure 3 and Figure 4 separately shows the deformation rate from January 2007 to January 2011 and the deformation rate from March 2015 to May 2017. The more redder color means the deformation is more serious. Figure 5 is the time-series deformation amount from January 2007 to January 2011. And Figure 6 is the time-series deformation amount from March 2015 to May 2017. They reflects the changing process of the deformation in the mining area.

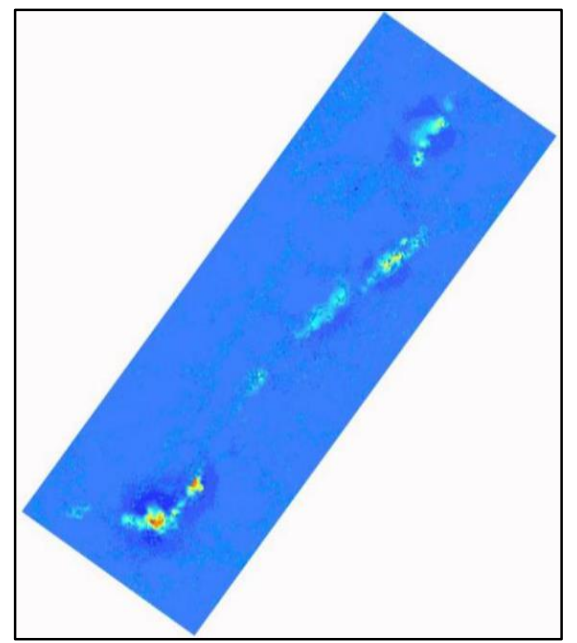

Figure 3. Deformation rate from 2007 to 2011

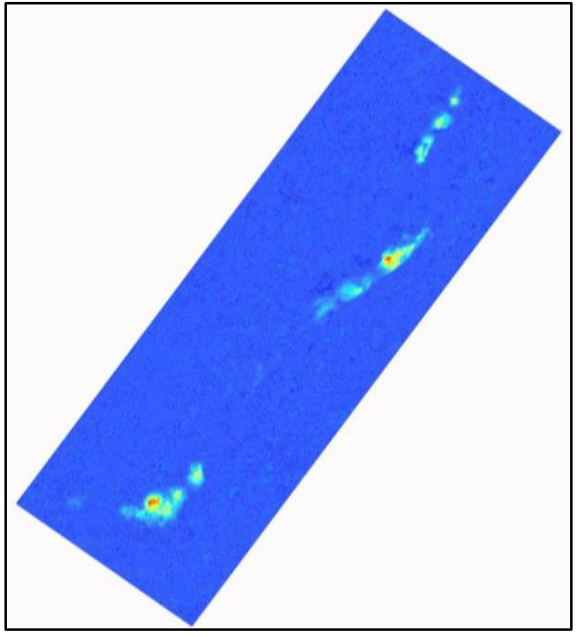

Figure 4. Deformation rate from 2015 to 2017 


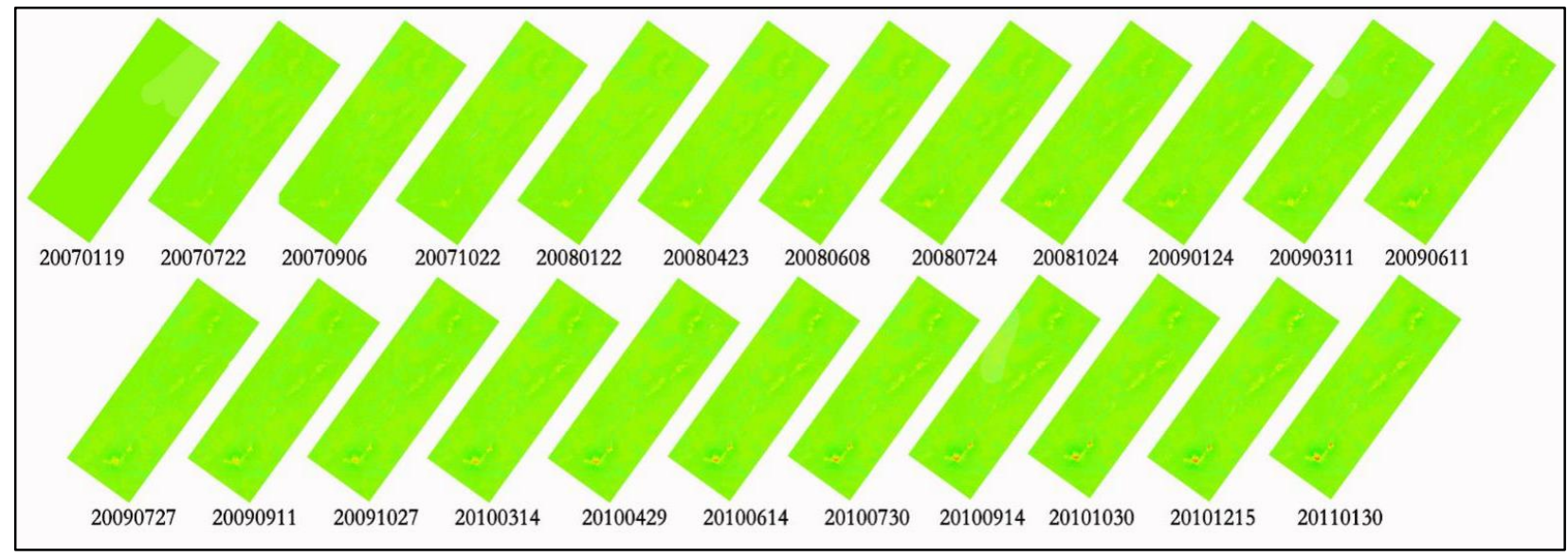

Figure 5. Deformation amount time-series change from 2007 to 2011

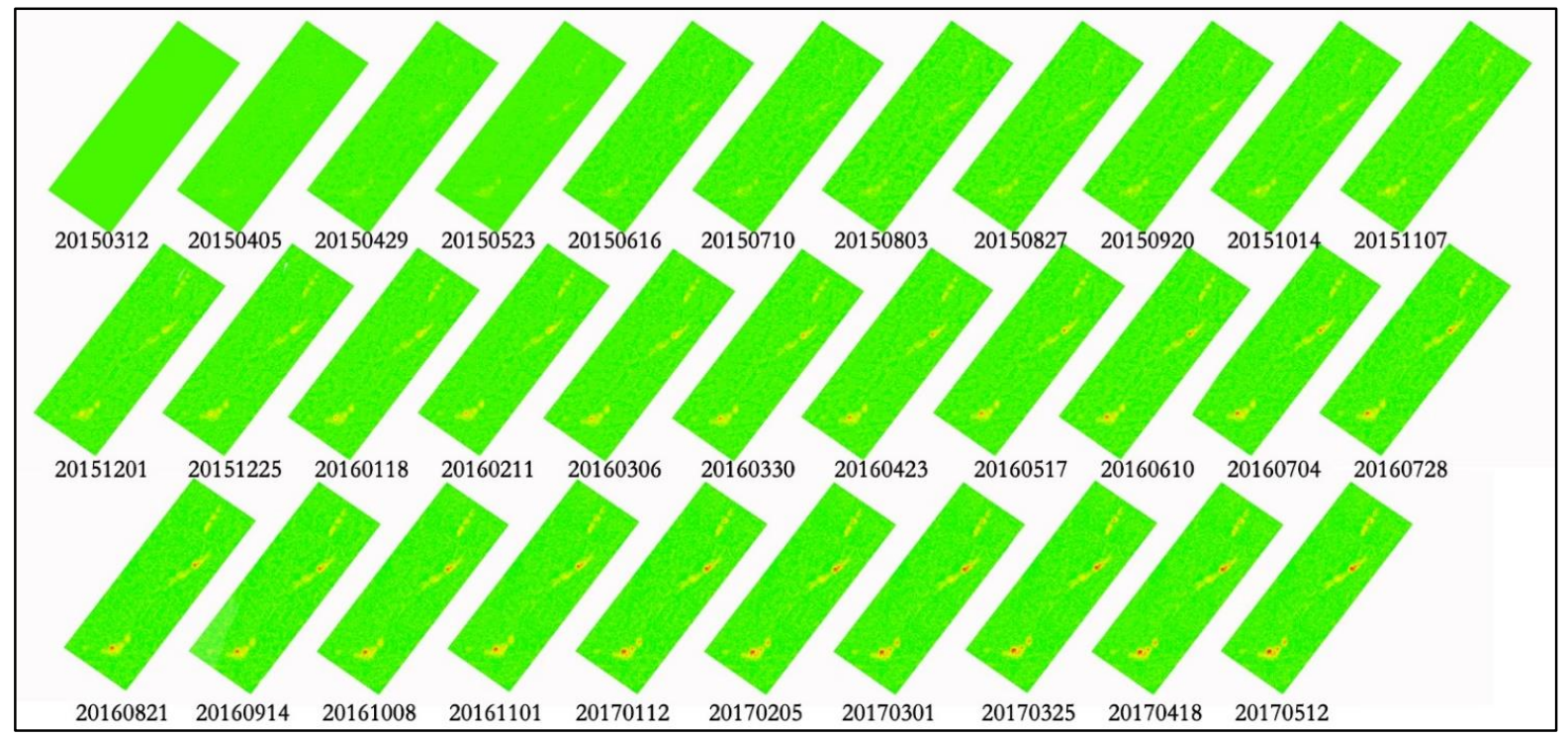

Figure 6. Deformation amount time-series change from 2015 to 2017

2.4.2 Deformation Area:In order to analysis the deformation conveniently, we obtain the deformation range according to the deformation rate. Base on value, we divide them into six degree, which are uplift area, slight deformation area, subsidence area from level 1 to 4 . Figure 7 is the detail dividing method, and the rate value equals $-10 \mathrm{~mm} / \mathrm{a}$ is defined as the settlement edge.

\begin{tabular}{|c|c|c|}
\hline \multirow{6}{*}{$\begin{array}{c}\text { Deformation } \\
\text { rate }\end{array}$} & $\begin{array}{c}\text { Level } 4 \\
\text { subsidence area }\end{array}$ & $\mathrm{V}<-100 \mathrm{~mm} / \mathrm{a}$ \\
\hline & $\begin{array}{c}\text { Level } 3 \\
\text { subsidence area }\end{array}$ & $V<-50 \mathrm{~mm} / \mathrm{a}$ and $V \geqslant-100 \mathrm{~mm} / \mathrm{a}$ \\
\hline & $\begin{array}{c}\text { Level } 2 \\
\text { subsidence area }\end{array}$ & $V<-30 \mathrm{~mm} / \mathrm{a}$ and $V \geqslant-50 \mathrm{~mm} / \mathrm{a}$ \\
\hline & $\begin{array}{c}\text { Level } 1 \\
\text { subsidence area }\end{array}$ & $V<-10 \mathrm{~mm} / \mathrm{a}$ and $V \geqslant-30 \mathrm{~mm} / \mathrm{a}$ \\
\hline & $\begin{array}{c}\text { Sight } \\
\text { deformation } \\
\text { area }\end{array}$ & $\mathrm{V}<10 \mathrm{~mm} / \mathrm{a}$ and $\mathrm{V} \geqslant-10 \mathrm{~mm} / \mathrm{a}$ \\
\hline & Uplift area & $\mathrm{V} \geqslant 10 \mathrm{~mm} / \mathrm{a}$ \\
\hline
\end{tabular}

Figure 7. Dividing method of the deformation range

According to the deformation range above, we found 7 subsidence areas, which distributes in a line from southwest to northeast forming a deformation zone. Figure 8 is the position of subsidence area in radar image. On the basis of the verification, all the subsidence areas are caused by coal mining.

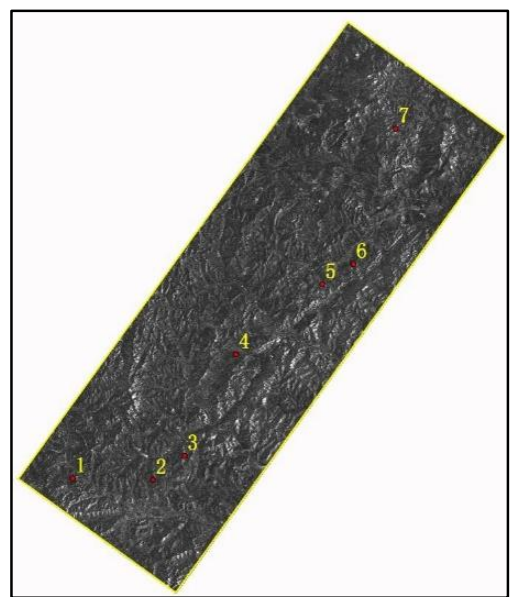

Figure8. The location of deformation area 


\subsection{Accuracy Verification}

The first stage data is archived data, and there is no comparable leveling data in this period from 2007 to 2011 , so its accuracy could not be verified. The second stage data is the programming data, during the data collection period, second-class leveling measurement is carried out. By comparing the accuracy of the leveling data with the monitoring results, the mean error of the rate meets the requirements of the technical design.

\section{TIME-SERIES ANALYSIS OF DEFORMATION MONITORING RESULTS}

\subsection{Explanation Before Analysis}

Since two stages data are involved, so two periods results will be explained next, including the influence range, deformation rate and deformation amount. But in fact, the results of the two periods could not be directly compared, because their reference datum are different. The first one is based on the situation in 2007 and the other is based on the situation in 2015. Therefore, the comparison in values is meaningless, but it can reflect the trends. So, the values discussed below are talking about the changes in the trends of the both.

\subsection{Range Analysis}

According to the method in 2.4, we get the edge of each deformation area. Here we count the acreage of each area, and analysis the changes between the two period data. Table 3 is the statistical result of the deformation range, it can be seen from the table that the changes in the deformation range of the two periods are prodigious. The range of deformation area $4 \#$ has been obviously reduced, after verification, it was found that the mine had stopped mining. The total area of the two periods increased from $1281.75 \mathrm{hm}^{2}$ in 4 years to $1326.41 \mathrm{hm}^{2}$ in 2 years. There is a big influence in a shorter time.

Table 3. Statistical results of deformation range

\begin{tabular}{|c|c|c|c|c|c|}
\hline \multicolumn{2}{|c|}{ First Stage Data Results } & \multicolumn{3}{c|}{ Second Stage Data Results } \\
\hline $\begin{array}{c}\text { Deformation Area } \\
\text { Number }\end{array}$ & $\begin{array}{c}\text { Affected area } \\
\left(\mathrm{hm}^{2}\right)\end{array}$ & $\begin{array}{c}\text { Affected Town } \\
\text { Number }\end{array}$ & $\begin{array}{c}\text { Deformation Area } \\
\text { Number }\end{array}$ & $\begin{array}{c}\text { Affected area } \\
\left(\mathrm{hm}^{2}\right)\end{array}$ & $\begin{array}{c}\text { Affected Town } \\
\text { Number }\end{array}$ \\
\hline Deformation Area 1\# & 46.86 & 1 & Deformation Area 1\# & 22.22 & 1 \\
\hline Deformation Area 2\# & 273.02 & 3 & Deformation Area 2\# & 426.14 & 4 \\
\hline Deformation Area 3\# & 84.55 & 2 & Deformation Area 3\# & 102.12 & 2 \\
\hline Deformation Area 4\# & 103.40 & 1 & Deformation Area 4\# & 11.72 & 1 \\
\hline Deformation Area 5\# & 272.03 & 3 & Deformation Area 5\# & 262.55 & 3 \\
\hline Deformation Area 6\# & 276.38 & 2 & Deformation Area 6\# & 269.33 & 2 \\
\hline Deformation Area 7\# & 225.51 & 2 & Deformation Area 7\# & 232.33 & 2 \\
\hline
\end{tabular}

\subsection{Rate Analysis}

In this paper, the deformation rate of two periods was analyzed, and table 4 is the statistical results. In the first stage, the maximum deformation rate reached $-192 \mathrm{~mm} / \mathrm{a}$ in deformation area $2 \#$. Besides, the maximum rate of deformation area $3 \#$ and deformation area $6 \#$ exceeds $-100 \mathrm{~mm} / \mathrm{a}$. In the second stage, the maximum deformation rate is in deformation area $7 \#$, the maximum deformation rate of deformation area $2 \#$ and deformation area $3 \#$ are $-114.49 \mathrm{~mm} / \mathrm{a}$ and $-85.02 \mathrm{~mm} / \mathrm{a}$. Although the results of two periods could not be compared directly, but we can see that they have changed a lot in value. Deformation area 1\#, 2\#, 3\#, 4\# and 6\# subsides slower, and deformation area $5 \#, 7 \#$ subsides faster.

Table 4. Statistical results of deformation rate

unit: $\mathrm{mm} / \mathrm{a}$

\begin{tabular}{|c|c|c|c|c|c|}
\hline \multicolumn{3}{|c|}{ First Stage Data Results } & \multicolumn{3}{c|}{ Second Stage Data Results } \\
\hline Deformation Area Number & maximum & mean & Deformation Area Number & maximum & mean \\
\hline Deformation Area 1\# & -39.50 & -17.58 & Deformation Area 1\# & -24.27 & -12.14 \\
\hline
\end{tabular}


The International Archives of the Photogrammetry, Remote Sensing and Spatial Information Sciences, Volume XLII-3, 2018

ISPRS TC III Mid-term Symposium “Developments, Technologies and Applications in Remote Sensing”, 7-10 May, Beijing, China

\begin{tabular}{|c|c|c|c|c|c|}
\hline Deformation Area 2\# & -192.40 & -51.38 & Deformation Area 2\# & -114.49 & -25.35 \\
\hline Deformation Area 3\# & -190.82 & -70.94 & Deformation Area 3\# & -85.02 & -22.64 \\
\hline Deformation Area 4\# & -85.71 & -20.18 & Deformation Area 4\# & -22.99 & -11.40 \\
\hline Deformation Area 5\# & -52.06 & -23.51 & Deformation Area 5\# & -93.73 & -25.94 \\
\hline Deformation Area 6\# & -122.91 & -38.71 & Deformation Area 6\# & -78.50 & -22.11 \\
\hline Deformation Area 7\# & -88.92 & -31.46 & Deformation Area 7\# & -129.45 & -28.24 \\
\hline
\end{tabular}

\subsection{Value Analysis}

After processing the data, except the deformation rate we can also obtain the deformation amount. By analyzing the amount, we can know the subside situation of each deformation area. The maximum value of annual variable and cumulated variable obtained can reflect the severity of the subsidence. Table 5 is the statistical result of cumulative variables in the two periods. During 2007 and 2011, the maximum value of the cumulative variable is $-675.08 \mathrm{~mm}$ in deformation $3 \#$, the maximum value of deformation area 2\# is $-652.06 \mathrm{~mm}$. During 2015 and 2017, the maximum value of the cumulative variable is $-279.75 \mathrm{~mm}$ in deformation area 7\#. Different from the first stage, the maximum value of the cumulative variable in deformation area $5 \#$ is bigger than that in deformation area 3\#. Table 6 is the statistical result of the annual variable, from it we can know the maximum value of annual variable from 2007 to 2011 turns out in deformation area $2 \#$ and deformation area $3 \#$ alternately. The maximum value of the annual variable from 2015 to 2017 is always in deformation area 7\#. So it can be seen that deformation area 2\# and deformation area $3 \#$ subsides more serious during the first stage, and deformation area 7\# subsides more serious during the second stage.

Table 5. Statistical results of the maximum value of cumulated variables

unit: $\mathrm{mm}$

\begin{tabular}{|c|c|c|c|c|c|c|c|c|}
\hline \multirow{2}{*}{ Data } & Time & $\begin{array}{c}\text { Deformation } \\
\text { area 1\# }\end{array}$ & $\begin{array}{c}\text { Deformation } \\
\text { area 2\# }\end{array}$ & $\begin{array}{c}\text { Deformation } \\
\text { area 3\# }\end{array}$ & $\begin{array}{c}\text { Deformation } \\
\text { area 4\# }\end{array}$ & $\begin{array}{c}\text { Deformation } \\
\text { area 5\# }\end{array}$ & $\begin{array}{c}\text { Deformation } \\
\text { area 6\# }\end{array}$ & $\begin{array}{c}\text { Deformation } \\
\text { area 7\# }\end{array}$ \\
\hline \multirow{3}{*}{$\begin{array}{c}\text { The first } \\
\text { stage }\end{array}$} & $2007-2008$ & -47.38 & -193.24 & -196.48 & -92.61 & -66.29 & -139.95 & -95.94 \\
\cline { 2 - 9 } & $2007-2009$ & -91.47 & -318.37 & -300.71 & -148.13 & -94.79 & -180.20 & -139.57 \\
\cline { 2 - 9 } & $2007-2011$ & -145.74 & -652.06 & -675.08 & -315.78 & -210.20 & -366.31 & -299.62 \\
\hline \multirow{2}{*}{$\begin{array}{c}\text { The } \\
\text { second } \\
\text { stage }\end{array}$} & $2015-2016$ & -35.67 & -119.02 & -95.70 & -30.67 & -101.60 & -92.12 & -142.37 \\
\cline { 2 - 9 } & $2015-2017$ & -52.60 & -241.21 & -183.40 & -54.87 & -202.94 & -170.86 & -279.75 \\
\hline
\end{tabular}

Table 6. Statistical results of themaximum value of the annual variable

unit: $\mathrm{mm}$

\begin{tabular}{|c|c|c|c|c|c|c|c|c|}
\hline \multirow{2}{*}{ Data } & Time & $\begin{array}{c}\text { Deformation } \\
\text { area 1\# }\end{array}$ & $\begin{array}{c}\text { Deformation } \\
\text { area 2\# }\end{array}$ & $\begin{array}{c}\text { Deformation } \\
\text { area 3\# }\end{array}$ & $\begin{array}{c}\text { Deformation } \\
\text { area 4\# }\end{array}$ & $\begin{array}{c}\text { Deformation } \\
\text { area 5\# }\end{array}$ & $\begin{array}{c}\text { Deformation } \\
\text { area 6\# }\end{array}$ & $\begin{array}{c}\text { Deformation } \\
\text { area 7\# }\end{array}$ \\
\hline \multirow{4}{*}{$\begin{array}{c}\text { The first } \\
\text { stage }\end{array}$} & $2007-2008$ & -47.38 & -193.24 & -196.48 & -92.61 & -66.29 & -139.95 & -95.94 \\
\cline { 2 - 9 } & $2008-2009$ & -49.58 & -131.54 & -104.24 & -55.52 & -44.62 & -64.18 & -46.20 \\
\cline { 2 - 9 } & $2010-2011$ & -28.37 & -172.76 & -172.63 & -73.25 & -50.67 & -103.11 & -68.56 \\
\hline \multirow{2}{*}{$\begin{array}{c}\text { The } \\
\text { second } \\
\text { stage }\end{array}$} & $2015-2016$ & -35.67 & -119.02 & -95.70 & -30.67 & -101.60 & -92.12 & -142.37 \\
\cline { 2 - 9 } & $2016-2017$ & -29.09 & -125.13 & -89.85 & -28.30 & -110.96 & -81.07 & -137.42 \\
\hline
\end{tabular}


From analysis rate and value, it could found that the most serious areas of deformation have changed. There may be two reasons: On one hand, the deformation rate in the subsidence area changed seriously; On the other hand, the subsidence area changed too much in a short time. When selected high coherence points, the settlement center do not have reliable points. Therefore, if calculating the maximum, the value decreases. Through the field verification, we find that the subsidence in deformation area $2 \#$ and deformation area $3 \#$ is still very serious. By analyzing the distribution of the highly coherent points, the second reason is more likely the truth.

\section{CONCLUSIONS}

Because the monitoring project is limited by some reasons, more detailed description of data processing and analysis results could not be made. But through analysis, it can be seen that:

(1)InSAR technology can monitor ground subsidence in large areas. It can reflect the subsidence phenomenon better, and meet the demand of subsidence monitoring in mining area. Using InSAR time-series technology to process the data can obtain the time-series change of the monitoring area, which is convenient for the subsequent subsidence analysis. If we can realize dynamic monitoring and share the results with other departments, it could provide a reference data for mine monitoring and management.

(2)Although the two stage data could not be compared directly, but we can still do some easy deformation trend analysis via value.

(3)Except mining area, InSAR technology can also be used to monitor subway, highway, railway and building accurately. Therefore, this method has a broad application space in the future.

\section{REFERENCES}

Ferretti A., Prati C, Rocca F., 1999. Non-Linear Subsidence Rate Estimation Using Permanent Scatterers in SAR Interferometry.// Proceedings of IEEE Geoscience and Remote Sensing Symposium. Hamburg: IEEE, 1999, pp. 1528-1530.

Hayman A., Ge L., Yan Y., 2010. Mapping accumulated mine subsidence using small stack of SAR differential interferograms in the Southern coalfield of New South Wales, Australia. Engineering Geology, 115(1/2), pp. 1-15.

Jiang L., Lin H., 2011. Potential of small-baseline SAR interferometry for monitoring land subsidence related to underground coal fires:Wuda(Northern China)case study.
Remote Sensing of Environment, 115(2), pp. 257-268.

Liu G., et al., 2005. Feasibility analysis of monitoring mining surface substance using InSAR-GPS data fusion. Bulletin of Surveying and Mapping, 2005(11), pp. 10-13.

Mora O., et al, 2001. Long-term Subsidence Monitoring of Urban Areas Using Differential Interferometric SAR Techniques.// Proceedings of IEEE Geoscience and Remote Sensing Symposium. Sydeney: IEEE, 2001, pp. 1104-1106.

Wang Z., Zhang J., Huang G., 2014. Precise monitoring and analysis of the land subsidence in Jining coal mining area based on InSAR technique. Journal of China University of Mining \&Technology, 43(1), pp. 169-174.

Yin H., et al., 2011. Ground subsidence monitoring in mining area using D-InSAR SBAS algorithm. Acta Geodaetica et Cartographica Sinica, 40(1), pp. 52-58.

Zhang Y., Wu H., Sun G., 2012. Deformation model of time series Interferometric SAR techniques. Acta Geodaetica et Cartographica Sinica, 41(6), pp. 864-869.

Zhang Y., et al., 2009. Monitoring urban subsidence based on SAR interferometric point target analysis. Acta Geodaetica et Cartographica Sinica, 38(6), pp. 482-487. 